\title{
UNA NUEVA DISPUTA ENTRE UN JUDÍO Y UN CRISTIANO EN UN MANUSCRITO DE LA BIBLIOTECA DE PALACIO (S. ¿XIV?)
}

\author{
AITOR GARCÍA MORENO \\ CSIC. Madrid
}

El texto del Coloquio entre un cristiano y un judio, cuya edición crítica tengo ultimada para publicación, se encuentra en el ms. 1344 de la Biblioteca de Palacio de Madrid. Adopto el título que, con caligrafia del siglo XVII, aparece en la segunda hoja de guarda del propio ejemplar, y también en el Catálogo de la Biblioteca ${ }^{1}$, frente a otras titulaciones como las presentes en el mismo manuscrito ${ }^{2}$, la dada por Serrano y Sanz y Manso Porto, que ofrece ligeras variantes ${ }^{3}$, o la genérica que propone Gómez Moreno en el estudio previo a su edición de la Gramática castellana de Palacio ${ }^{4}$, otro de los textos del manuscrito, no exenta de problemas ${ }^{5}$.

El manuscrito, tal y como recoge el Catálogo, está escrito sobre papel en tamaño cuarto y presenta encuadernación moderna (siglo XIX) con dos hojas de guarda al inicio y otras dos al final. Como advirtió Gómez Moreno, contiene tres textos distintos y consta de 119 folios numerados modernamente en

\footnotetext{
' Catálogo de la Real Biblioteca: mantuscritos, Madrid, Patrimonio Nacional, 1994, vol. 1, pág. 636.

${ }_{2}$ También en letra del siglo xvll, en la primera hoja de guarda: Colloquio entre el christiano y judio, y en el tejuelo: COLLOQUIO ENTRE UN CHRISTIANO Y JUDIO.

${ }^{3}$ Ambos lo citan corno Colloquio entre el christiano y el judio: M. Serrano y Sanz en su articulo «Libros manuscritos o de mano [de la biblioteca del Conde de Gondomar]», en $R e$ vista de Archivos, Bibliotecas y Museos, VIII, 65-68, 1903, pág. 225; y C. Manso Porto en su libro Don Diego Sarmiento de Acuña, Conde de Gondomar (1567-1626): erudito, mecenas y bibliófilo, Xunta de Galicia, 1996, pág. 619.

${ }_{4}$ A. Gómez Moreno lo denomina Disputa entre un cristiano y un judio en su artículo "Gramática castellana de Palacio: un nuncio de Nebrija», en Revista de Literatura Medieval, 1, 1989, págs. 43-44.

${ }^{5}$ Vid. N. Salvador Miguel, «Consideraciones sobre el Debate entre un cristiano y un judío" en Comentario de textos literarios, M. Crespillo y J. Lara Garrido (eds.), (= Analecta Malacitana, anejo IX), Málaga, Universidad de Málaga, 1997, pág. 48.
}

RFE, LXXXIl, 2002, 1.-2., págs. 185-189 
el ángulo superior derecho del recto (numeración por la cual cito), y a veces también en el ángulo inferior. De los tres textos, el Coloquio ocupa desde el folio 1 recto al 112 vuelto y el 119 recto y vuelto, en tanto que un fragmento de una Gramática va del $113 \mathrm{r}$ al $116 \mathrm{v}$, y un tercer texto de contenido moral ocupa los folios 117 y 118 . La numeración consecutiva consignada en todos ellos pasa por alto el desorden con que están encuadernados los folios del Coloquio a juzgar por las signaturas y reclamos que, con caligrafia del $\mathrm{xv}$, presenta el texto; por más que muchos de ellos sean dificilmente apreciables o se hayan perdido por la acción de la cuchilla del encuadernador.

Tales signaturas aparecen en el ángulo inferior izquierdo del vuelto, y consisten en la numeración romana de cada uno de los pliegos que conforman los distintos cuadernos de que se compone el códice. Asimismo, en el vuelto del último folio de cada cuaderno aparece un reclamo consistente en la primera o primeras palabras del texto del primer folio del cuaderno siguiente. Así, encontramos cuatro reclamos distintos: «rogase» (f. 22v), «engañadon» (f. 40v), «cabdillo» (f. 64v) y «casa q[ue] es» (f. 78v). Atendiendo a dichos reclamos, el Catálogo señala la extensión en folios de los distintos cuadernos que componen el códice como de $22+18+24+14+16$ (debiera decir 35 , pues tales son los folios hasta el final del texto, o aun 37 si tenemos en cuenta que considera el Tratado moral como perteneciente al Coloquio), suponiendo lagunas en el texto y advirtiendo de algunos errores de encuadernación. Sin embargo, según la correcta ordenación que mi edición propone atendiendo a los contextos y a las citadas signaturas en números romanos, el Coloquio se compone, sí, de 5 cuadernos (que llamaremos A, B, C, D y E), pero de 11, 14, 12,14 y 7 pliegos de dos folios respectivamente. El texto de la Gramática ocupa dos pliegos, y el Tratado moral sólo un pliego ${ }^{6}$.

\footnotetext{
${ }^{6} \mathrm{~A}$ mi entender, no existen tales lagunas en el texto y los principales desajustes se han producido por aparecer fuera de su sitio los últimos pliegos del cuaderno B (pliegos X al XIIII) y los últimos pliegos del cuaderno D (pliegos VIII al XIIII), insertos todos dentro de! cuaderno E, de la siguiente manera: Pliego B-XIIII, inserto doblado a continuación de E-IIIa (folio izquierdo resultante de doblar el pliego por la mitad): su inclusión aquí se entiende en la medida en que la $X$ de $X I I I I$ aparece cortada y más separada del resto de to habitual, to que habria podido llevar a una mala lectura de $X I I I /$ por $I I I I$. Pliegos D-VIII y D-IX, insertos abiertos tras E-VII; lo que resulta comprensible si tenemos en cuenta que a un pliego con el número VII le segutrían otros con los números VIIl y IX, aunque de distinto cuaderno. Pliegos B-X, B-XI, B-XII y B-XIII, insertos abiertos a continuación del citado D-IX, de nuevo presentando numeración consecutiva. Pliegos D-X, D-XI, D-XII, D-XIII y D-XIIII, insertos abiertos dentro de B-XIII; aquí, la razón del equívoco podría estar en que apenas se lee el número en D-X, falta el de D-XI y, aunque sí aparece el número en D-XII, de nuevo falta éste en D-XIII. Por su parte los dos pliegos en los que aparece la Gramática aparecen insertos doblados juntos tras $\mathrm{E}-\mathrm{Vb}$ (folio de la derecha), y a continuación, también doblado, el pliego con el Tratado moral, todos antes de E-llilb. Al final faltarian las tres hojas correspondientes a la sección b de los pliegos E-III, E-II y E-I, que estando en blanco habrian sido arrancadas con anterioridad a la encuadernación.
} 
Los tres textos están escritos en castellano a línea tirada: el Coloquio y la Gramática en letra gótica redonda del siglo $\mathrm{xv}$, pero de manos diferentes, con una anotación al final de la Gramática en el folio $116 \mathrm{v}$, en gótica cursiva; de mano también distinta, el Tratado moral está todo escrito en letra gótica cursiva. En todos ellos falta la suscripción del copista, quedando sin notar ni el autor, ni el lugar ni la fecha de composición.

El Catálogo de la Biblioteca de Palacio fecha la copia del Coloquio en el siglo XV; copia muy de finales del siglo a juzgar por el trazo de algunas letras. Sin embargo, el texto contiene dos pasajes en los que se da la fecha de composición. Por un lado se lee,

E verás q[ue] onrra dio Dios a su fijo Jesucristo, $\mathrm{q}[\mathrm{ue}]$ lo adoraro[n] e adora[n] de cada día todos los cristianos de mil e trezie[n]tos e sete[n]ta años pasados acá q[ue] nasçió (folio 86r, líneas 8-11);

y por otro:

¿no[n] sabes q[ue] son pasados mil e trezie[n]tos e sete[n]ta años q[ue] Jesucristo vino? (f. 112v:13-15).

Por tanto, podemos adelantar la composición del original hasta 1370, pues el texto se refiere concretamente al tiempo transcurrido desde el nacimiento de Cristo, y dado que no aparece referencia alguna a los sucesos de 1391, que sin duda marcaron un antes y un después en las relaciones entre judios y cristianos.

El Coloquio se nos presenta así, como la disputa teológica conservada más extensa escrita en castellano en época medieval, y casi la más antigua, sólo superada en antigüedad por la famosa Disputa entre un cristiano y un judio $^{7}$, de mitad del siglo XIII.

El texto del Coloquio, organizado en 13 capítulos de diferente extensión, trata distintos aspectos de la doctrina cristiana que se pretende exponer, siemre en contraposición con las creencias y prácticas judías. El primero, el más stenso de todos (ff. 1r-31v, 90r-93v, 82r-83v, 104r-107v y 32r-38v), gira en no a la cuestión de la identificación de la figura de Jesucristo con la del ias prometido en la Ley. Para ello, se tratan también cuestiones relativas igen divino de Cristo y a la Santisima Trinidad, con constantes alusiones

rublicada por A. Castro («Disputa entre un cristiano y un judio», en $R F E, 1$, 1914, págs. 173-180), fue estudiada luego por G. Giménez Resano ("Anotaciones lingüisticas a la "Disputa entre un cristiano y un judio"», en Actas Terceras Jornadas de estudios Berceanos, Logrởo: díc. 1979, 1981, págs. 91-100), y más tarde por A. Salvador Plans, («Disputa entre un cristiano y un judio: essudio lingüísticon, en Glosa, 1, 1990, págs. 59-97). Véase también la puesta al día de N. Salvador Miguel, Debate entre un cristiano y un judio: un texto del siglo XIII. Avila, Caja de Ahorros de Ávila, 2000. 
a los dichos de los profetas y a su interpretación cristológica. El segundo, algo menos extenso (ff. 39r-69r), se centra en la figura de Santa Maria, su virginidad y papel como Madre de Dios, desde el análisis de las profecías que la anuncian. El resto de los capítulos, mucho más breves, tienen como núcleo central los siguientes temas, algunos ya apuntados en los capítulos precedentes, si bien son constantes las vueltas sobre los dos ejes centrales citados: Jesucristo $=$ Mesías $=$ hijo de Dios, y Santa María $=$ virgen $=$ madre de Dios. Así, el tercero (ff. 69v-70v) analiza el sacramento del sacerdocio; el cuarto (ff. 71, 88r-89v y 94) justifica la iconografia cristiana de Cristo y los mártires; el quinto (ff. 95r-97v) se ocupa del descanso dominical; el sexto (f. 98) trata sobre el sacramento del bautismo; el séptimo (ff. 99r-100v) aborda el sacramento de la penitencia; el octavo (ff. 101r-102r) defiende los enterramientos cristianos junto a los templos; el noveno (ff. $102 \mathrm{v}-103 \mathrm{v}, 108 \mathrm{r}-109 \mathrm{v}$ y 72r-73v) habla sobre la observancia de los mandamientos de Dios; el décimo (ff. 74r-76v) analiza la figura del diablo; el undécimo (ff. 77r-80v) trata distintos dogmas de fe, como la esperanza en la resurrección de los muertos y la vida eterna, la omnipotencia de Dios, etc.; el duodécimo (ff. 81 y 84r-85r) defiende la práctica cristiana de la señal de la cruz, y el décimo tercero (ff. $85 \mathrm{v}-87 \mathrm{v}, 110 \mathrm{r}-112 \mathrm{v}$ y 119 ) recapitula cuestiones tratadas en los anteriores.

Sin embargo, el interés y valor del texto no radican únicamente en el tratamiento de cuestiones de ámbito teológico, lugares comunes en la controversia judeo-cristiana la mayor parte de ellas, sino en la introducción de contenidos de otra índole, eso sí, como apoyatura argumentativa a la hora de defender los dogmas y prácticas cristianos.

De este modo, por ejemplo, es frecuente el recurso a la Gramática a la hora de defender desavenencias en el orden de la exégesis bíblica:

ca dixiera el testo «caerá» en la lengua futura, e non en la pasada [...] en [e] dicho paçú $\mathrm{q}$ [ue] dize "como caiste» e no[n] dize "como caerás", q[ue] demuestra "caiste» cosa pasada e no[n] cosa por venir (ff. 74v:27-28 y 75 r:21-23);

la introducción de conceptos filosóficos:

los filosofos [...] dezía[n] q[ue] avía[n] quatro causas e q[ua]tro razon[e]s de cada cosa criada. E q[ue] la una dezía[n] que era fazedera, e la otra q[ue] .era de q[ué] se fazía, e la otra q[ue] era forma e man[er]a de $q$ [ue] se fazía, e la otra q[ue] era final razó[n] a q[ue] se fazía (f. $78 \mathrm{v}: 19-20$ y $22-28$ ),

o la alusión a hechos históricos, aun a costa de caer en el anacronismo:

dize[n] las istorias q[ue] estando los gentiles enojados de matar de tus padr[e]s, por escarnio tomaro[n] navios sin remos e sin viandas, e metiero[n] 
en los navios judíos todos ma[n]çebos, e no[n] viejos ni[n] muger[e]s ni[n] criaturas, e dexáro[n]los ir por la mar así como que peresçiesen; e el vie[n]to echólos la mar ayuso e aportaron en Aragó[n] e en Granada (f. $84 \mathrm{r}: 19-26$ ).

Todos estos comentarios traídos al hilo de la controversia teológica, junto con el sinfin de referencias a libros bíblicos y tratados talmúdicos o midrásicos de que está salpicado el texto (unas 350), no hacen sino dar buena muestra del saber cultural de la época.

No faltan tampoco las estampas de tipo costumbrista, a la hora de comentar la diferencia de prácticas entre judíos y cristianos:

despecho me toma $\mathrm{q}[\mathrm{ue}]$ vo a la $\mathrm{n}$ [uest\}ra carneçería e trayo una pierna de carnero, e qua[n]to saca mi mug[e]r el sevo e las venas e los nervios, cuido q[ue] tengo carne e qua[n]do lo pone ant[e] mí parésçeme $\mathrm{q}[u e]$ tengo una torta de huevos ant[e] mí, ansí como me lo saca de la olla (f. 109r:1-6).

Todo el texto muestra un estilo vivo pese a la gravedad de los temas tratados, jocoso y mordaz en ocasiones, con un espléndido manejo de las técnicas del diálogo. Destaca así, en el plano de la organización discursiva, la maestría en la sucesión de los turnos de habla, articulados según un esquema de preguntas y respuestas, con abundantes formulaciones de carácter deíctico, deixis personal y social. Por otra parte, en la estructuración de argumentos y contraargumentos, son relevantes: la introducción de argumentos de autoridad y exempla; la glosa o paráfrasis de términos o conceptos, bien mediante la fórmula explícita «quiere dezir», bien mediante la adición de sinónimos; la topicalización de constituyentes (SN o SP) con reduplicación del elemento nexual en cláusulas completivas de Complemento Directo, como procedimiento de énfasis; la recursividad de cláusulas de tipo causal-consecutivo (con nexos como «ca», «porque», «pues»), o adversativo (nexos «mas», «pero»), y la explicitación de conclusiones con fórmulas del tipo «por ende», «e ansí», etc. Todo ello, con un léxico rico y variado donde no falta la adaptación ortográfica de frecuentes hebraísmos como «almá»

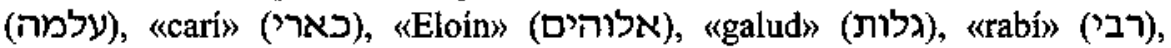
«seguiná» (שכלנה), (טרפה), etc.

Elementos unos y otros que, tanto en el fondo como en la forma, hacen interesante el texto no sólo al investigador, sino también al lector curioso en general. 